\title{
Effectiveness of Risk Stratification According to CHADS2 Score in Japanese Patients With Nonvalvular Atrial Fibrillation
}

\author{
Nobuyuki Masaki, ${ }^{1}$ MD, Makoto SuzUKI, ${ }^{2} \mathrm{MD}$, Ryota IwATsuKa, ${ }^{2} \mathrm{MD}$, \\ Akira MizuKAmi, ${ }^{2}$ MD, Leon KumasaKa, ${ }^{2}$ MD, Wataru NAGAHORI, ${ }^{2}$ MD, \\ Masakazu OHno, ${ }^{2} \mathrm{MD}$, Akihiko Matsumura, ${ }^{2} \mathrm{MD}$, \\ Yoshiaki MARuYAma, ${ }^{3} \mathrm{MD}$, and Yuji Hashimoto, ${ }^{2} \mathrm{MD}$
}

SUMMARY

Cerebrovascular events increase with additional risk factors in patients with nonvalvular atrial fibrillation (NVAF). The relative risk proportional to the number of risk factors in Japanese patients has not been reported.

The prevalence of risk factors was investigated for over 2 years in a prospective cohort study of 265 patients with NVAF. The CHADS2 score is a widely used risk stratification scheme that includes age, hypertension, diabetes mellitus, previous stroke, and heart failure.

Cerebral infarction occurred in 23 patients. This group was significantly older and had a significantly higher prevalence of hypertension. The ratio of a CHADS2 score of 0 - 2 was $77 \%$ among patients without stroke, but $44 \%$ in the cerebral infarction group. Univariate logistic regression analysis showed that the predictive factors of cerebral infarction were: age (odds ratio (OR) 1.087 (confidence interval $(\mathrm{CI}) 1.032-1.145, P=0.002$ ), hypertension (OR 3.288 (CI $1.086-9.962, P=0.03$ ) and CHADS2 score (OR 1.762 (CI $1.222-2.543, P=0.002)$. Furthermore, a CHADS2 score of $3-6$ was associated with a greater risk of cerebral infarction (OR 4.420 (CI $1.838-10.631, P<0.001$ ).

The CHADS2 score was a useful marker of stroke risk in this Japanese population. An increased CHADS2 score was associated with an approximate 1.8-fold increase in risk. (Int Heart J 2009; 50: 323-329)

Key words: Atrial fibrillation, Stroke

THE rate of cerebral infarction increases with additional risk factors in patients with nonvalvular atrial fibrillation (NVAF). The CHADS2 score is a popular

From the ${ }^{1}$ Department of Cardiology, Saitama Medical Center, Saitama Medical University, Kawagoe, ${ }^{2}$ Department of Cardiology, Kameda Medical Center, Kamogawa, ${ }^{3}$ Department of Health Promotion, Saitama Medical Center, Saitama Medical University, Kawagoe, Japan.

Address for correspondence: Nobuyuki Masaki, MD, Department of Cardiology, Saitama Medical Center, 1981 Kamoda Tsujido, Kawagoe, Saitama 350-8550, Japan.

Received for publication October 16, 2008.

Revised and accepted January 16, 2009. 
method of evaluating accumulated risk $^{1-3)}$ and to determine the choice of anticoagulation therapy. ${ }^{4}$ However, the effectiveness of the scheme in Japanese patients has not been fully determined.

\section{Methods}

We prospectively observed 306 patients with atrial fibrillation between December 2005 and December 2007 at the outpatient clinic of Kameda Medical Center, Kamogawa, Japan. The exclusion criterion was severe valvular disease requiring valve replacement surgery. Patients who could be not examined before the end of the observation period were also excluded from the analysis.

The endpoint was cerebral infarction caused by thromboembolism or atherosclerosis. Transient ischemic attack (TIA) was included when hospitalization was considered necessary.

The physicians in charge determined the administration of warfarin for each patient. Cerebrovascular risk was assessed based upon the following definitions. Hypertension was identified as blood pressure above 160/95 $\mathrm{mmHg}$ or preceeding medication. Diabetes mellitus and hyperlipidemia were defined as a fasting plasma glucose $\geq 126 \mathrm{mg} / \mathrm{dL}$ or use of insulin or oral hypoglycemic agents, and total cholesterol $\geq 220 \mathrm{mg} / \mathrm{dL}$ or medication, respectively. Paroxysmal atrial fibrillation was recognized by conversion to sinus rhythm in electrocardiograms. Left ventricular diameters in systolic and diastolic phase were derived from baseline M-mode echocardiography. Ejection fraction of the left ventricle was calculated by either M-mode or 2-dimensional (2D) echocardiography.

The CHADS2 score is a risk stratification system for NVAF patients. ${ }^{2)}$ Scores of 0 to 6 points are determined based on the following factors: congestive heart failure ( 1 point); hypertension ( 1 point); age over 75 years ( 1 point); diabetes mellitus ( 1 point); and previous stroke or TIA ( 2 points). In the risk scheme, scores of 0,1 to 2, and 3 to 6 reflect low risk, intermediate risk, and high risk, respectively.

All data were statistically analyzed using Stat View version 5.0 (Abacus USA). All values are expressed as the mean \pm standard deviation. Scales among 3 groups were compared using Student's $t$ test. For nominal parameters, either the Chi square test or Fisher exact test was selected. The occurrence of cerebral infarction was examined using univariate logistic regression analysis. A value of $P<0.05$ was considered significant for all results. 


\section{RESULTS}

Patients: We enrolled 293 patients because 13 patients were lost during the observation. Among the 293 patients, 19 had already undergone valve replacement surgery and 9 required new valve surgery. Risk of cerebral infarction was finally assessed in the 265 patients. The average of the duration to reach the endpoint was $703 \pm 88$ days.

Cerebrovascular events: Table I compares the baseline characteristics of patients with and without cerebral infarction. Cerebral infarction occurred in 23 patients $(8.7 \%)$, and none developed TIA. The mean age was significantly older and hypertension was more frequent among patients with cerebral infarction. The rates of previous cerebral infarction and cardiovascular disease did not differ between the two groups. Warfarin was prescribed for 182 patients $(67 \%)$ and another 15 started using warfarin during the observation period. Three patients started using

Table I. Patient Characteristics

\begin{tabular}{|c|c|c|c|c|}
\hline Parameter & $\begin{array}{l}\text { All patients } \\
(n=265)\end{array}$ & $\begin{array}{c}\text { Cerebral } \\
\text { infarction }(+) \\
(n=23)\end{array}$ & $\begin{array}{c}\text { Cerebral } \\
\text { infarction }(-) \\
(n=242)\end{array}$ & $P$ value \\
\hline Age, years & $72 \pm 11$ & $80 \pm 8$ & $72 \pm 11$ & 0.001 \\
\hline Male & $172(65 \%)$ & $12(52 \%)$ & $160(66 \%)$ & 0.210 \\
\hline BMI, $\mathrm{kg} / \mathrm{m}^{2}$ & $23 \pm 3.4$ & $23 \pm 4.3$ & $23 \pm 3.3$ & 0.620 \\
\hline Hypertension & $162(61 \%)$ & $19(83 \%)$ & $143(59 \%)$ & 0.027 \\
\hline Hyperlipidemia & $80(30 \%)$ & $8(35 \%)$ & $72(30 \%)$ & 0.616 \\
\hline Diabetes mellitus & $71(27 \%)$ & $9(39 \%)$ & $62(26 \%)$ & 0.162 \\
\hline Smoking & $75(30 \%)$ & $7(30 \%)$ & $75(30 \%)$ & 0.973 \\
\hline CHADS2 score & & & & 0.003 \\
\hline 0 & $39(15 \%)$ & $1(4 \%)$ & $38(16 \%)$ & \\
\hline $1-2$ & $158(60 \%)$ & $9(39 \%)$ & $149(62 \%)$ & \\
\hline $3-4$ & $65(25 \%)$ & $12(52 \%)$ & $53(22 \%)$ & \\
\hline $5-6$ & $3(1 \%)$ & $1(4 \%)$ & $2(1 \%)$ & \\
\hline Paroxysmal atrial fibrillation & $10(4 \%)$ & $1(4 \%)$ & $9(4 \%)$ & 0.880 \\
\hline Cerebral infarction & $31(12 \%)$ & $3(13 \%)$ & $28(12 \%)$ & 0.834 \\
\hline Heart failure & $35(13 \%)$ & $4(17 \%)$ & $31(13 \%)$ & 0.535 \\
\hline Myocardial infarction & $17(6 \%)$ & $3(13 \%)$ & $14(6 \%)$ & 0.175 \\
\hline CABG & $6(2 \%)$ & 0 & $6(2 \%)$ & 0.445 \\
\hline PCI & $16(6 \%)$ & $3(13 \%)$ & $13(5 \%)$ & 0.140 \\
\hline Pacemaker & $16(6 \%)$ & $1(4 \%)$ & $15(6 \%)$ & 0.722 \\
\hline \multicolumn{5}{|l|}{ Medications } \\
\hline Aspirin & $141(53 \%)$ & $14(61 \%)$ & $127(52 \%)$ & 0.441 \\
\hline Warfarin* & $182(67 \%)$ & $13(57 \%)$ & $169(70 \%)$ & 0.188 \\
\hline Discontinuation & $3(1 \%)$ & $1(4 \%)^{* *}$ & $2(1 \%)$ & 0.239 \\
\hline Initiation & $15(6 \%)$ & $4(17 \%) \#$ & $11(5 \%)$ & 0.031 \\
\hline Ticlopidine hydrochloride & $6(2 \%)$ & 0 & $6(2 \%)$ & 0.445 \\
\hline
\end{tabular}

Data are number $(\%)$ or mean \pm standard deviation. CABG indicates coronary artery bypass grafting; PCI, percutaneous coronary intervention; *, Warfarin group includes patients who discontinued warfarin during the observation period; **, A patient stopped warfarin after cerebral infarction and \#, One and three patients started warfarin before and after cerebral infarction occurred, respectively. 
warfarin after cerebral infarction. The average of PT-INR was $1.89 \pm 0.31$.

Left ventricular diastolic diameter tended to be smaller in the cerebral infarction group (Table II). However, left atrial diameter and left ventricular ejection fraction did not differ between the groups.

Other events: Six deaths (Table III) occurred, including 3 cardiac deaths (2 myocardial infarctions and 1 acute heart failure) and 3 deaths from other causes ( 1 colon cancer and 2 sudden deaths of unknown etiology).

None of the patients died from cerebral infarction or intracranial hemorrhage. One major hemorrhagic event occurred in a patient on warfarin, who had intracranial hemorrhage associated with trauma. Minor hemorrhagic events occurred in 4 patients, including gastrointestinal hemorrhage in a patient who did not take warfarin. Subcutaneous hemorrhage developed in 3 patients on warfarin.

Table II. Echocardiographic Measurements

\begin{tabular}{lcccc}
\hline & $\begin{array}{c}\text { All patients } \\
(n=265)\end{array}$ & $\begin{array}{c}\text { Cerebral } \\
\text { infarction }(+) \\
(n=23)\end{array}$ & $\begin{array}{c}\text { Cerebral } \\
\text { infarction }(-) \\
(n=242)\end{array}$ & $P$ value \\
\hline LVDd (mm)* & $49 \pm 7$ & $47 \pm 6$ & $49 \pm 7$ & 0.068 \\
LVDs (mm)** & $32 \pm 8$ & $30 \pm 7$ & $33 \pm 8$ & 0.203 \\
LAD (mm)* & $49 \pm 8$ & $50 \pm 7$ & $49 \pm 8$ & 0.442 \\
LVEF (\%)\# & $62 \pm 12$ & $59 \pm 15$ & $62 \pm 12$ & 0.259 \\
\hline
\end{tabular}

LVDd indicates left ventricular diastolic diameter; LVDs, left ventricular systolic diameter; LAD, left atrial diameter; LVEF, left ventricular ejection fraction; \#, Four patients each with cerebral infarction $(+)$ and (-) were lost and $* *$, Eight patients with cerebral infarction (-) were lost. All data are shown as the mean \pm standard deviation. Two patients with cerebral infarction (-) were lost.

Table III. Follow-up Events

\begin{tabular}{lcccc}
\hline & $\begin{array}{c}\text { All patients } \\
(n=265)\end{array}$ & $\begin{array}{c}\text { Warfarin }(+) \\
(n=182)\end{array}$ & $\begin{array}{c}\text { Warfarin }(-) \\
(n=83)\end{array}$ & $P$ value \\
\hline All deaths & $6(2 \%)$ & $2(1 \%)$ & $4(5 \%)$ & 0.059 \\
$\quad$ Cardiac death & $3(1 \%)$ & $1(0.5 \%)$ & $2(2 \%)$ & 0.184 \\
$\quad$ Noncardiac death* & $3(1 \%)$ & $1(0.5 \%)$ & $2(2 \%)$ & 0.184 \\
Cerebral infarction & $23(9 \%)$ & $13(7 \%)$ & $10(12 \%)$ & 0.188 \\
Major bleeding** & $1(0.4 \%)$ & $1(0.5 \%)$ & 0 & 0.499 \\
Minor bleeding\# & $4(1 \%)$ & $3(2 \%)$ & $1(1 \%)$ & 0.784 \\
Heart failure & $18(7 \%)$ & $9(5 \%)$ & $9(11 \%)$ & 0.077 \\
Myocardial infarction & $8(3 \%)$ & $5(3 \%)$ & $3(4 \%)$ & 0.702 \\
CABG & $3(1 \%)$ & $2(1 \%)$ & $1(1 \%)$ & 0.940 \\
PCI & $7(3 \%)$ & $6(3 \%)$ & $1(1 \%)$ & 0.325 \\
Pacemaker & $3(1 \%)$ & $3(2 \%)$ & 0 & 0.240 \\
\hline
\end{tabular}

*indicates Noncardiac death includes sudden death of unknown cause; **, Major bleeding defined as extracranial fatal bleeding or hemorrhagic shock needing blood transfusion or surgery, and intracranial hemorrhage including hemorrhagic stroke; \#, Minor bleeding is any hemorrhage other than major bleeding; CABG, coronary artery bypass grafting and PCI, percutaneous coronary intervention. 
Risk analysis: Low and intermediate risk patients comprised $78 \%$ in the group without events (Table I) and high-risk patients with CHADS2 scores of 3 - 6 comprised $56 \%$ of the cerebral infarction group. The incidence rate of stroke proportionally increased with the score (Figure). Among the patients who were not on warfarin, the event rates (number of stroke patients/all patients) of CHADS2 scores of $0,1-2,3-4$, and 5 - 6 were 0 (0/7), 7.7\% (4/48), 21.7\% $(5 / 18)$, and $100 \%(1 / 1)$, respectively. Among the patients who were on warfarin, these values were $3.1 \%(1 / 32), 4.7 \%(5 / 106), 16.7 \%(7 / 42)$, and $0(0 / 2)$, respectively.

Univariate logistic analysis demonstrated that significant prognostic factors for cerebral infarction were age, hypertension, and CHADS2 score (Table IV). CHADS2 scores of 3 - 6 were associated with a greater risk of cerebral infarction. The relative risk was about 4.4. The CHADS2 scores were not assessed by multivariate analysis because the scheme takes age and hypertension into account.

The types of predictive factors were unchanged by warfarin therapy. The risk factors of patients with warfarin therapy were age (OR 1.082 (CI 1.005 $1.166, P=0.04$ ) and CHADS2 score (OR 1.575 (CI $0.997-2.489, P=0.05$ ), while those of patients without warfarin were age (OR 1.097 (CI $0.999-1.203$, $P=0.05)$ and CHADS2 score (OR 2.145 (CI $1.118-4.118, P=0.02)$. Hyper-

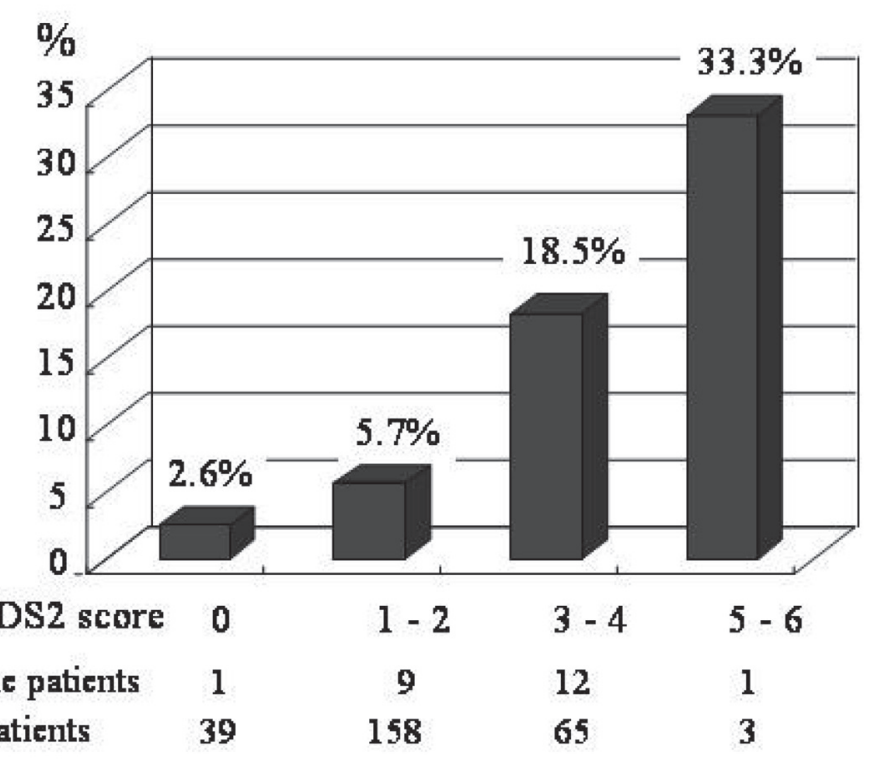

Figure. Incidence of stroke over 2 years. 
Table IV. Univariate Logistic Regression Analysis

\begin{tabular}{lccc}
\hline & OR & CI & $P$ value \\
\hline Age* & 1.087 & $1.032-1.145$ & 0.002 \\
Hypertension & 3.288 & $1.086-9.962$ & 0.034 \\
Diabetes mellitus & 1.866 & $0.770-4.525$ & 0.167 \\
Cerebral infarction & 1.147 & $0.320-4.098$ & 0.834 \\
Heart failure & 1.433 & $0.457-4.484$ & 0.537 \\
Warfarin & 0.561 & $0.236-1.339$ & 0.193 \\
CHADS2 score* & 1.762 & $1.222-2.543$ & 0.002 \\
CHADS2 $\geqq 3$ & 4.420 & $1.838-10.631$ & $<0.001$ \\
\hline
\end{tabular}

* indicates by unit increase; OR, odds ratio and CI, confidence interval.

tension was not statistically significant in the subgroup analysis. In addition, the severity of risk determined by CHADS2 score did not affect the effectiveness of warfarin therapy (low and intermediate risk; OR 1.600 (CI $0.516-6.012, P=$ 0.37), (high risk; OR 1.600 (CI $0.434-5.893, P=0.48)$.

\section{Discussion}

The CHADS2 score was an independent prognostic factor for cerebral infarction in NVAF patients as reported. ${ }^{5)}$ We proved that risk increased approximately 1.8 -fold according to the CHADS2 score. Our results demonstrated that this scoring system has predictive power regardless of warfarin administration. A previous study showed that the significance of the CHADS2 score was inferior for Japanese patients on antiplatelet therapy and that the score became partially dissociated with the incidence of stroke in patients on warfarin. ${ }^{6}$ However, high-risk patients defined by the CHADS2 scheme had a high rate of stroke despite receiving warfarin.

The overall event rate of $8.7 \%$ for 2 years in the present study was slightly higher than that in a previous article. ${ }^{7)}$ However, the mean age of our patients was about 5 years older than theirs. Age is one of the most important risk factors for stroke, because the prevalence of other risk factors generally increases with age. ${ }^{8)}$ Other guidelines have simply categorized patients under 65 years old with no other risk factors as being of low risk. ${ }^{9-11)}$ Two strokes occurred in the subgroup of 63 patients who were younger than 65 years. The predictive value of the CHADS2 score might have been clearer in the more elderly population in our study.

Chamber size and left ventricular function had relatively little influence on stroke as reported in a guideline. ${ }^{3)}$ Left ventricular diastolic diameter was paradoxically smaller in stroke patients. Left atrial diameter tended to be larger in patients on warfarin therapy ( $50 \pm 8$ versus $48 \pm 8 \mathrm{~mm}, P=0.096)$. The size of the left atrium on transthoracic echocardiograms is less associated with the 
prevalence of thromboembolism under appropriate anticoagulation. ${ }^{3)}$ On the other hand, our study also suggested that warfarin alone cannot prevent cerebral infarction in the elderly. To evaluate the effectiveness of anticoagulation, further investigation of warfarin control in individual patients is warranted.

This study has several limitations. Firstly, we had a small patient cohort. Secondly, we did not distinguish cardiac thromboembolism from other causes of stroke. Thirdly, warfarin therapy was not randomized for evaluation as a prognostic factor. The interpretation of warfarin effectiveness was limited because a control was not assessed in this study and a few patients started or discontinued warfarin during the observation period.

In conclusion, the CHADS2 score was useful in Japanese population. Individual risk factors should be managed and anticoagulation therapy should be applied to patients at high risk according to CHADS2 scores.

\section{REFERENCES}

1. Rietbrock S, Heeley E, Plumb J, van Staa T. Chronic atrial fibrillation: Incidence, prevalence, and prediction of stroke using the Congestive heart failure, Hypertension, Age > 75, Diabetes mellitus, and prior Stroke or transient ischemic attack (CHADS2) risk stratification scheme. Am Heart J 2008; 156: 57-64.

2. Gage BF, Waterman AD, Shannon W, Boechler M, Rich MW, Radford MJ. Validation of clinical classification schemes for predicting stroke: results from the National Registry of Atrial Fibrillation. JAMA 2001; 285: 2864-70.

3. Fuster V, Rydén LE, Cannom DS, et al. ACC/AHA/ESC 2006 guidelines for the management of patients with atrial fibrillation--executive summary: a report of the American College of Cardiology/ American Heart Association Task Force on Practice Guidelines and the European Society of Cardiology Committee for Practice Guidelines (Writing Committee to Revise the 2001 Guidelines for the Management of Patients With Atrial Fibrillation). J Am Coll Cardiol 2006;48: 854-906.

4. Gage BF, van Walraven C, Pearce L, et al. Selecting patients with atrial fibrillation for anticoagulation: stroke risk stratification in patients taking aspirin. Circulation 2004; 110: 2287-92.

5. Baruch L, Gage BF, Horrow J, et al. Can patients at elevated risk of stroke treated with anticoagulants be further risk stratified? Stroke 2007; 38: 2459-63.

6. Inoue H, Nozawa T, Hirai $\mathrm{T}$, et al. Accumulation of risk factors increases risk of thromboembolic events in patients with nonvalvular atrial fibrillation. Circ J 2006; 70: 651-6.

7. Tomita F, Kohya T, Sakurai M, et al. Prevalence and clinical characteristics of patients with atrial fibrillation: analysis of 20,000 cases in Japan. Jpn Circ J 2000; 64: 653-8.

8. Stroke Risk in Atrial Fibrillation Working Group. Independent predictors of stroke in patients with atrial fibrillation: a systematic review. Neurology 2007; 69: 546-54. (Review)

9. Fang MC, Go AS, Chang Y, et al. Comparison of risk stratification schemes to predict thromboembolism in people with nonvalvular atrial fibrillation. J Am Coll Cardiol 2008; 51: 810-5.

10. Risk factors for stroke and efficacy of antithrombotic therapy in atrial fibrillation. Analysis of pooled data from 5 randomized trials. Arch Intern Med 1994; 154: 1449-57.

11. Singer DE, Albers GW, Dalen JE, Go AS, Halperin JL, Manning WJ. Antithrombotic therapy in atrial fibrillation: the Seventh ACCP Conference on Antithrombotic and Thrombolytic Therapy. Chest 2004; 126: 429S-56S. (Review) 